\title{
A EDUCAÇÃO DAS CRIANÇAS PEQUENAS COMO ESTRATÉGIA PARA O “ALÍVIO” DA POBREZA*
}

\author{
Rosânia Campos** \\ Roselane Fátima Campos***
}

\section{RESUMO}

O objetivo desse artigo é discutir as indicações destinadas à educação infantil produzidas por organismos internacionais. De modo específico, analisamos dois projetos em ação na América Latina, sendo um coordenado pela Unesco e outro pela OEI. Neste trabalho, estudamos os principais documentos produzidos no âmbito desses projetos, observando as concepções e a lógica que os sustentam, suas divergências e similitudes. Segundo as indicações destes, a educação infantil é uma importante estratégia no combate à pobreza e um meio para promover a equidade, sendo seu foco as crianças e famílias que vivem em "situação de vulnerabilidade social". Em consequência, a educação infantil é caracterizada como um serviço, afastando-se da concepção de um bem público que deve ser garantido como direito às crianças e famílias.

Palavras-chave: Educação infantil. Políticas públicas. Organismos internacionais. Educação e redução da pobreza.

Este trabalho tem como objetivo apresentar uma análise de dois projetos em desenvolvimento na América Latina e no Caribe: A Agenda Ibero-Americana para a Infância e a Adolescência (AIIA), coordenado pela Organização dos Estados Ibero-Americanos (OEI), e o Projeto Regional de Educação para a América Latina e Caribe (Prelac), coordenado pela Unesco. Apesar de guardarem diferenças entre si, ambos

* Artigo recebido em 30/06/2008 e aprovado em 13/10/2008.

** Doutora em Educação, professora do Programa de Pós-Graduação em Educação da Universidade do Sul de Santa Catarina (PPGE/Unisul), pesquisadora do NUPEIN/UFSC. E-mail: rosania. campos@unisul.br

*** Professora da Universidade Federal de Santa Catarina e do Programa de Pós-Graduação em Educação (PPGE/UFSC). E-mail: roselane@ced.ufsc.br 
os projetos têm como foco a educação compreendida como meio eficaz para a promoção da equidade social. Ainda que de modo diferenciado, ambos os projetos contêm orientações, metas e estratégias destinadas à educação das crianças pequenas. Fazem parte do que em outro estudo designamos como uma "agenda globalmente estruturada para a educação infantil" (CAMPOS, 2008). As fontes dessa agenda podem ser encontradas em diferentes acordos, pactos e convenções ocorridas deste o início da década de 1990; destes, destacamos dois pelas relações diretas com os projetos que acima mencionamos: a Conferência Mundial de Educação para Todos (Jomtien) e a Cúpula Mundial pelos Direitos da Infância. O Prelac filia-se diretamente à primeira - representa em nível regional o compromisso dos governos locais com as metas do Plano de Ação da Conferência; já a AIIE (Agenda Ibero-Americana para a Infância e Adolescência), é tributário dos compromissos assumidos pelos governos ibero-americanos com a Cúpula Mundial.

Para bem compreender estes projetos e o que estamos designando como uma "agenda globalmente estruturada para a educação infantil", recorremos à análise dos documentos produzidos pela OEI e Unesco, no âmbito dos projetos referidos ou complementares a estes. Partimos do pressuposto de que documentos elaborados por diferentes instâncias governamentais e organismos internacionais têm se mostrado um terreno fértil para compreendermos não apenas as mudanças na/da política, como também os contextos sociais mais amplos que estão em suas origens. De acordo com Shiroma, Campos e Garcia (2005, p. 429), documentos são relevantes "tanto porque fornecem pistas sobre o como as instituições explicam a realidade e buscam legitimar suas atividades, quanto pelos mecanismos utilizados para sua publicização". Com o surgimento das novas tecnologias de informação, a circulação de documentos tornou-se mais rápida, a disseminação de documentos tornou-se massiva, popularizando um conjunto de informações e justificativas legitimadoras das reformas (Shiroma; CAMPos; Garcia, 2005).

Nesse contexto, também podemos observar os papéis assumidos pelos organismos internacionais, pois, mesmo que estes não sejam estreantes na organização das diferentes agendas dos países, nas últimas décadas seus papéis têm sido de uma relevância inédita (ANTUNES, 2005b). Isto porque a busca por construir um discurso hegemônico não é um processo que ocorra passivamente. Este processo é sempre mediado por várias lutas, disputas, resistências, acordos etc. Este terreno de disputas 
não se restringe somente a disputas conceituais. Não podemos esquecer que políticas são, ao mesmo tempo, processo e resultados. Além destes fatores, há que se considerar também que todas estas intervenções, tanto em nível técnico (com a produção dos relatórios, estudos, indicadores, propostas, modelos) quanto em nível econômico, são mediadas pela posição dos países na estratégia de poder no sistema mundial e por sua capacidade interna de resistir (EvangELISTA, 2005).

Referenciando-nos então a esses pressupostos, apresentamos, na sequência deste artigo, as concepções e pressupostos que têm orientado os projetos em análise, destacando as relações destes com as políticas de contenção à pobreza difundidas, em especial, pelo Banco Mundial. Procuramos explicitar ainda as indicações para as políticas destinadas às crianças de 0-3 anos o papel reservado às famílias e aos modos não-formais de atendimento. Enfim, procuramos evidenciar os pressupostos que informam as políticas focais e compensatórias, principal indicação dos projetos e dos organismos que os coordenam para os países da região.

\section{A EDUCAÇÃO DA INFÂNCIA COMO INVESTIMENTO ECONÔMICO}

Um mundo apropriado para as crianças! Este foi o lema que reuniu milhares de organismos internacionais, representantes de organizações sociais e chefes de Estado na última década do século XX, na Cúpula Mundial pelos Direitos da Infância, patrocinada pela Organização das Nações Unidas. O objetivo era a construção de uma agenda política destinada a responder às questões que tornam a infância contemporânea uma "nova questão social". Justificativas a parte, de fato, são incontestáveis as condições impróprias de vida de grande parte das crianças na atualidade. Esta "agenda", articulada especialmente por organismos internacionais, tais como Unesco, Unicef, Banco Mundial e outros que atuam mundialmente, tem forte poder mobilizador nas diferentes regiões do mundo, seja pela atuação direta destes organismos no financiamento de programas de baixo custo, seja por sua inserção indireta, atuando como indutores de políticas locais, via acordos e pactos partilhados com os governos nacionais. Embora com diferenças em seus modus operandi, os discursos destes organismos convergem nos argumentos e nas justificativas que usam para legitimar suas proposições e estratégias de ação: apresentam um forte apelo humanitário, centrado na denúncia das condições de pobreza, violência e exclusão social que atingem milhares de crianças 
no mundo. Apesar das intenções proclamadas, constatamos, no entanto, que as soluções propostas não apontam na direção da superação das condições sociais que produzem aquilo que denunciam.

Com as reformas estruturais observadas nas últimas décadas do século XX, as desigualdades sociais foram ampliadas, gerando tanto um incremento da pobreza quanto o surgimento dos denominados "novos pobres", fato que obrigou os Estados a buscarem alternativas para "contornar" essa situação e "garantir a governabilidade", todavia, sem tomar como base o preceito da ampliação dos direitos sociais. Nesta direção, a educação ganha uma centralidade estratégica, associada a uma "nova" lógica econômica. Passa a ser proclamada, por diferentes organismos e governos nos anos 1990, como "eixo da produtividade com equidade", difundindo-se a idéia de que a oportunidade de acesso seria a via para a promoção da equidade social. Acrescenta-se assim uma nova função à educação que passa a ser vista como uma "ferramenta eficaz" no combate à pobreza. Isto porque se supõe que a distribuição equitativa de oportunidades educacionais pode gerar, como contrapartida, "taxas de retorno" positivas, traduzidas em benefícios sociais e econômicos para os indivíduos, rompendo assim com o "ciclo vicioso da pobreza".

Ademais, é sempre bom lembrar que o crescimento da pobreza, em escala mundial e particularmente na América Latina e no Caribe, é também resultado dos ajustes estruturais fomentados e induzidos pelos mesmos organismos que defendem, atualmente, as políticas para "combater" e/ou "aliviar a pobreza". Porém, ressaltamos, nas análises destes, a pobreza não é tratada como um problema estrutural e conjuntural, mas sim como uma questão residual dos processos de reformas estruturais dos Estados, cujos desdobramentos resultaram em desenvolvimento inadequado.

A educação, tomada como estratégia para o alívio da pobreza, sustenta-se ainda na lógica das políticas redistributivas compensatórias, contrária, em sua essência, às bases que ancoram as políticas redistributivas estruturais. Nessa perspectiva, as causas estruturais da pobreza não são atacadas, e o que é fomentado é o desenvolvimento de políticas compensatórias focalizadas. Em consequência, há uma "reorientação da universalidade para a operação de diferentes programas estratégicos e compensatórios da assistência focalizada na linha da pobreza segundo diferentes "públicos-alvo" (Ivo, 2004, p. 59). 
Com relação às indicações para a educação infantil, podemos observar também a presença dessas concepções. A educação das crianças pequenas tem suscitado grande interesse nestes organismos, o que pode ser constatado tanto pelas ações como recomendações aos governos para que invistam neste nível educativo (CEPAL, 1995; ONU, 2002; UNICEF, 2006; UnESCO, 2007). Para dar legitimidade aos seus discursos, observamos a recorrência, nos documentos produzidos por estes organismos, a estudos realizados por economistas que enfatizam a importância do investimento na educação infantil, assegurando que este é o investimento social mais rentável para a sociedade (Heckman, 2000; Heckman e CunHa, 2005). Exemplo desta perspectiva pode ser observada no Informe de educação para todos (2007), no qual se destaca que

de um ponto de vista econômico, os investimentos em programas para a primeira infância são muito rentáveis em capital humano, o qual constitui um poderoso argumento para reclamar uma intervenção dos poderes públicos neste âmbito. Esses programas não são só vantajosos para as crianças e as famílias, mas também contribuem para reduzir a desigualdade social e redundam em benefícios para comunidades e as sociedades em seu conjunto. (UNESCO, 2007, p. 116, tradução livre)

Cabe ainda destacar que as reformas educacionais implementadas na América Latina referenciaram-se largamente às concepções e aos pressupostos acima discutidos. No caso brasileiro, a reforma guardou ainda estreita relação com a reforma do Estado, processo este que redefiniu as relações entre a esfera pública e privada, com implicações significativas para a educação infantil. A focalização no ensino fundamental, por exemplo, repercutiu fortemente na questão do financiamento para a educação infantil, produzindo como consequência uma expansão pouco significativa de sua oferta, notadamente para as crianças de 0-3 anos.

Isso nos faz concluir que, apesar dos avanços reconhecidos em termos de legislação, de fato, na prática, temos um "quase-direito", posto ser muito desigual o acesso das crianças a este nível educacional, quer se considere os indicadores regionais, quer os níveis etários. Ainda que o direito das crianças pequenas (0-6 anos) tenha sido reconhecido na Constituição de 1988, como direito a ser provido pelo Estado, observamos uma larga distância entre o direito proclamado e o efetivado. De acordo com dados da PNAD/IBGE (2006), apenas 15,5\% das crianças 
nas faixas etárias entre 0 e 3 anos frequentam alguma instituição de educação infantil. Os contrastes também são significativos quando consideramos as regiões do país. Nesse caso, Norte e Nordeste são aquelas com as menores taxas de atendimento em creches: respectivamente, $8 \%$ e 13,3\%, enquanto Sul e Sudeste apresentam as mais elevadas $(19,2 \%$ e $18,3 \%$ ). Estamos longe, portanto, da meta acordada no Plano Nacional de Educação, para 2005: 30\% das crianças de 0-3 anos em creches públicas. Contrariamente, entre as crianças de faixas etárias mais próximas da escolarização obrigatória, observamos indicadores mais condizentes com as metas: $76 \%$ das crianças entre $4-6$ anos, no Brasil, já frequentam alguma instituição educativa (PNAD/IBGE, 2006). Estes dados se tornam ainda mais significativos quando os comparamos com os pressupostos que sustentam o Plano Nacional de Educação (2001), no que tange a educação infantil; observamos que, diante de tão grande demanda, a recomendação é a prioridade para as crianças provenientes dos segmentos mais "vulneráveis" da população.

Com estes destaques, marcamos rapidamente alguns aspectos da "agenda local" que se encontram em consonância com indicações encontradas na "agenda global" e nos projetos regionais.

\section{A EDUCAÇÃO INFANTIL COMO ESTRATÉGIA PARA A PROMOÇÃO DA EQUI- DADE SOCIAL}

Como já mencionamos anteriormente, as indicações dos organismos internacionais atuantes na América Latina têm enfatizado ações e programas organizados com base na lógica das políticas focais e compensatórias, tendo como alvo principal o alivio às situações de pobreza. Preservadas as diferenças entre eles, identificamos três estratégias que lhes são comuns: a) o acento na educação das mulheres; b) o disciplinamento das famílias e c) a indicação de programas de atendimento de baixo custo. Dessa forma, a educação infantil é apresentada e discutida nestes projetos como uma medida compensatória, que deve privilegiar, como anunciam, as crianças e famílias em situação vulnerável. Vale ainda registrar que os discursos de corte economicistas mantêm interfaces com os discursos que tomam a criança como sujeito de direitos, criando assim representações e imagens híbridas deste direito, na medida em que ocultam a estreita relação entre os direitos e a condição social de classe. Exemplifica essa convergência discursiva a Agenda Ibero-Americana 
para Infância e Adolescência (AIIA). Embora dê centralidade à criança como sujeito de direitos, as análises das Conferências Ibero-Americanas de Educação que antecederam à formulação da AIIA, e lhe deram suporte, indicam que, ao mesmo tempo em que a agenda é estruturada com base no reconhecimento dos direitos das crianças, a educação infantil é discutida como estratégia para atingir a equidade, como fator para "compensar desigualdades", conforme podemos observar na Declaração da IX Conferência Ibero-Americana de Educação:

A educação inicial para favorecer um melhor desempenho dos meninos em graus posteriores e como fator de compensação de desigualdades. (Oei. Declaração de Havana. IX Conferência de Educação, 1999, grifos nossos)

Ou ainda como é destacado na X Conferência Ibero-Americana de Educação:

Que a educação inicial é um dos fatores estratégicos para garantir a equidade, diminuir os efeitos da pobreza e promover a justiça em prol da consolidação da democracia, a convivência social, assim como o apoio ao desenvolvimento econômico e a competitividade de nossos países. (Oei. Declaração de Havana. X Conferência de Educação, 2000, grifos nossos)

Assim, parece que ao considerarem a educação como estratégia para combater a pobreza e/ou garantir a equidade existe uma defesa e uma compreensão de que o simples acesso às instituições de educação infantil e à escola garantirá a superação das questões socioeconômicas postas. No entanto, ainda que o acesso à educação seja uma condição necessária, ela não é suficiente para retirar da pobreza os milhões de pessoas que nela vivem. Este fato tem sérias repercussões no reconhecimento e na execução dos direitos sociais e, no caso específico da criança, mesmo que nos documentos ela seja sempre referida como "sujeito de direitos", esse reconhecimento não é efetivado, uma vez que a própria organização dos Estados não é compatível com a aceitação da criança como sujeito e ator econômico com suas próprias necessidades e funções (WINTERBERGER, 2006).

Não é possível, portanto, considerar que essas indicações, que acabam por ratificar as políticas de combate à pobreza, possam ser con- 
sideradas como indicações para a consolidação de políticas sociais. De acordo com Ziccardi (2001, p. 86):

as políticas sociais são a garantia de que se busca a equidade social e a promoção dos direitos básicos da cidadania. Porém é algo muito diferente de políticas de redução da pobreza, que buscam tirar das condições de miséria aqueles que não alcançaram o piso básico da sobrevivência.

Ainda que em sua agenda a OEI pretenda voltar-se para todas as crianças e adolescentes, não explicita as responsabilidades dos Estados no provimento de uma educação infantil de qualidade. Em suas metas e ações estratégicas, a ênfase é dada à preparação e/ou à educação das famílias para educar as crianças. Assim, se, por um lado, há um acento no direito das crianças à educação, por outro, transfere-se para a família e a comunidade a responsabilidade de sua execução. Trata-se de oportunizar, incentivar, desenvolver estratégias que capacitem os pais a criar seus filhos, não de qualquer modo, mas do modo "certo", isto é, desenvolvendo "toda" a potencialidade da criança. Dois pressupostos embasam essas orientações: a) a perspectiva de desenvolvimento infantil como seguindo uma linha de desenvolvimento dada a priori, o que possibilita pensar a educação da criança com o objetivo de potencializar seu desenvolvimento; e b) a idéia dos pais como primeiros educadores das crianças, e, para tanto, a necessidade de educá-los.

Em relação à perspectiva de desenvolvimento infantil adotada, dá-se grande ênfase aos aportes da neuropsicologia como fundamento para a educação das crianças pequenas. Dessa forma, sua educação é entendida como uma "oportunidade", tendo em vista que os primeiros anos de vida são considerados cruciais para o desenvolvimento posterior. Assim se afirma na AIIA:

é possível obter avanços muito importantes no combate à pobreza e à pobreza extrema se nós assegurarmos que as crianças tenham o melhor começo possivel de vida durante os primeiros anos, que recebam atenção na saúde, estimulação precoce adequada, educação de boa qualidade, e que os adolescentes tenham oportunidades amplas de exercer seus direitos e de se converter em pessoas responsáveis. Em outras palavras, garantindo os direitos humanos desde a primeira infância e criando oportunidades do desenvolvimento integral. (OEI. Declaração de Lima. Agenda IberoAmericana para a Infância e a Adolescência, 2001b, grifos nossos) 
Essa concepção de desenvolvimento da criança e de sua educação é também ressaltada no documento de referência da X Conferência Ibero-Americana de Educação (2000), no qual se afirma que a adequada educação está relacionada com o desenvolvimento cerebral, sendo que somente nos primeiros períodos de vida é possível apreender certas habilidades que, mais tarde, tornam-se difíceis de serem dominadas. E isto justificaria a necessidade de

oferecer estimulação precoce no lar e ter um diagnóstico precoce dos problemas que podem limitar a aprendizagem (hiperatividade, disfunções, audição ou dano cerebral). (OEI. Declaração do Panamá. X Conferência Ibero-Americana de Educação, 2000a)

Essa perspectiva que ressalta a estimulação de potencialidades e não a compensação de carências fundamenta-se também na compreensão do desenvolvimento infantil como um processo universal, que pode ser potencializado pela oferta adequada e eficiente de estímulos externos; deriva dessa concepção a necessidade de "educar" os pais para que possam estimular e criar oportunidades de aprendizagens adequadas para seus filhos. Enfim, parte-se do pressuposto de que todas as crianças nascem "potencialmente educáveis", mas nem sempre seu contexto social favorece esse desenvolvimento, logo, a saída é a "preparação" das famílias para que, desde o seu nascimento, possam propiciar às crianças um conjunto de dispositivos e atitudes "que conformam a base que condiciona e torna possível as aprendizagens posteriores" (TEDEsco, 2002, p. 11). Isto é, na perspectiva da educabilidade, as lógicas socializadoras das famílias devem ser objeto de intervenção, atuando-se no sentido de aproximar estas daquelas inerentes ao "modo escolar de socialização", por meio de uma "pedagogização das relações sociais de aprendizagem" (Thin, 1998, p. 27, apud CAMPos; CAMPOS, 2006).

Uma análise da meta seis da AIIA, além de reafirmar o acima discutido com relação à educação das crianças e de suas famílias, informa-nos também que a perspectiva da estimulação precoce parece se aplicar melhor às crianças menores de três anos, retomando-se, neste documento, a antiga dualidade na educação das crianças pequenas: para crianças menores de três anos, a referência são os "serviços socioeducativos"; já para as crianças maiores de três anos, a indicação é "educação". Esta divisão também repercutiu na definição das demais metas da AIIA, 
observando-se a presença de indicadores quantitativos determinados apenas para as crianças maiores de três anos, ao passo que, para as de idade inferior, fala-se apenas em "ampliar", sem indicação de metas de atendimento ou de prazo para isto. Assim, na meta seis da AIIA, encontramos a indicação para:

Ampliar a cobertura dos serviços socioeducativos para meninos e meninas de 0 a 3 anos com amplo horário e garantir para o ano de 2015 o acesso universal à educação pré-escolar (3-6 anos); sustentada nos princípios da não discriminação, da qualidade, da equidade e respeito a multiculturalidade. (Oei. Declaração de Lima. Agenda Ibero-Americana para a Infância e a Adolescência, 2001b, grifos nossos)

Para além do acima discutido, observamos ainda nessa meta uma tendência a desconsiderar a extensão do direito universal à educação para as crianças menores de três anos. Parece que ainda se pauta na lógica de que a educação para menores de três anos é indicada para os pobres dentre os pobres, desempenhando função de guarda; diferentemente da pré-escola que, em geral, é associada a programas educacionais e destinadas a todos numa associação direta com a escolaridade obrigatória (ROSEMBERG, 1989).

Tendo em vista essas concepções, a AIIA enfatiza a importância da educação via ambiente familiar, destacando a necessidade de se pensar na educação das mães, principais agentes desse processo. Assim, na Declaração da XI Cúpula "Unidos para Construir o Amanhã", ${ }_{1}^{1}$ os chefes de Estados reconhecem:

o valor e a importância da mulher ibero-americana na promoção do desenvolvimento econômico, social e cultural das nossas sociedades, para a qual reiteramos o nosso compromisso de garantir os seus direitos e eliminar os obstáculos que impeçam o seu acesso aos recursos produtivos e a sua participação plena e equitativa na sociedade. Neste sentido, daremos especial atenção à sua participação nos programas de erradicação da pobreza, através da criação de oportunidades de formação profissional, segurança ou seguridade social e acesso ao crédito, entre outros. (Grifos nossos)

A indicação da mulher como a pessoa mais adequada para educar/ cuidar dos filhos não é uma novidade; pelo contrário, após a Segunda 
Guerra Mundial, foram vários os estudos, no Ocidente, que discutiram as consequências do afastamento das crianças de suas mães, desenvolvendo críticas em relação à institucionalização das crianças. Argumentava-se nesses estudos que a institucionalização provocava problemas irreversíveis no desenvolvimento da criança, em especial nas crianças menores de três anos. A defesa da permanência da mulher na vida privada acabou por ratificar a subordinação de gênero, além de dificultar a participação social e política das mulheres. Parece que atualmente vivemos um revival dessas premissas, atribuindo-se à mulher não apenas um papel afetivo, mas também a responsabilidade pela diminuição das taxas de desnutrição e mortalidade infantil, além de e elevar o aproveitamento escolar de seus filhos. E nesse contexto:

as mulheres com escolaridade incompleta merecem "cursos de mães", com verbas da educação infantil e não uma formação completa como cidadãs no contexto da educação de jovens e adultos [...]. (ROSEMBERG, 2002b, p. 24)

Essa orientação não é uma exclusividade da AIIA. Conforme podemos observar no Projeto Regional de Educação para a América Latina e Caribe (PRELAC), a educação, sobretudo das crianças nas faixas etárias de zero a três anos, é compreendida como uma tarefa das famílias. No documento de "Modelo de Acompanhamento - Apoio, Monitoramento e Avaliação" do Projeto Regional de Educação para a América Latina e Caribe (PRELAC), nas linhas de ação prioritárias, no quarto eixo, foi definido: universalização da educação infantil, apresentando a necessidade de proporcionar aos países alternativas para qualificação e habilitação de especialistas em:

a) identificação da população de 0 a 6 anos sem atendimento educacional;

b) preparação e implementação de programas educacionais, com enfoque intersetorial e caráter comunitário, que promovam:

- o importante papel da família na educação das crianças.

- o atendimento a outras necessidades da família como a alfabetização, a educação quanto a aspectos da saúde e nutrição, bem como o enriquecimento cultural. (Unesco/Prelac, 2002b) 
Nesse documento é ainda destacada a necessidade de implementar e fortalecer a formação e capacitação dos responsáveis pela educação infantil, bem como a formulação e implementação de um sistema de acompanhamento e monitoramento da qualidade dos programas de atendimento à primeira infância. No que se refere ao papel das famílias na educação das crianças pequenas, essa indicação pode ser observada também na Declaração de Havana, ${ }^{2}$ quando se afirma:

o cuidado e o desenvolvimento integral da primeira infância com enfoque centrado fundamentalmente na família e na generalizado do acesso à educação inicial deve ser o pilar fundamental de toda boa educação, por isso se deve aumentar os programas educativos para a atenção à infância de zero a seis anos, com uma participação protagônica da família e com base na comunidade, utilizando as mais melhores experiências da área e ampliar sua cobertura. (Unesco. Declaração de Havana, 2002)

Essa participação protagônica da família é reforçada também no próprio documento do PRELAC, quando se afirma que:

é na família que se inicia o processo de educação das pessoas e é onde se estabelecem os primeiros vínculos afetivos e cognitivos. A escola deve contemplar a educação familiar e considerar os pais como os primeiros educadores de seus filhos e estabelecer com eles o diálogo e a cooperação, tendo como objetivo comum o desenvolvimento pleno das crianças e jovens. (Unesco/Prelac, 2002 , grifos nossos)

Ao observarmos as afirmações acima é possível destacar dois aspectos: a) concepção de educação infantil como "atenção" e/ou "cuidado e desenvolvimento" da criança; b) educação das famílias para os cuidados das crianças, em especial, para a saúde e nutrição. Em relação ao primeiro aspecto - concepção de educação infantil como "atenção" e/ou "cuidado e desenvolvimento" -, observamos que esta denominação tanto pode expressar uma ampliação do enfoque do atendimento infantil, que contemplaria, além da educação, a área da saúde e nutrição, quanto pode significar a ratificação de modelos não-formais de educação infantil. Segundo Rosemberg (2002a), a expressão "desenvolvimento infantil" é sempre utilizada nos documentos para designar educação infantil nos países subdesenvolvidos. Para os países desenvolvidos, a expressão utilizada é "educação infantil". Esse fato não implica em apenas uma 
diferenciação de nomes, antes revela a concepção de educação infantil subjacente a cada nome; ao mesmo tempo, em países subdesenvolvidos como o Brasil, a expressão desenvolvimento infantil pode auxiliar para burlar a

regulamentação educacional que preconiza padrões institucionais e profissionais para a EI: formação profissional prévia dos professores, respeito à legislação trabalhista, proporção adulto-criança; instalações e equipamentos. Ao escapar da regulamentação o custo do projeto cai, evidentemente, em detrimento da qualidade. (Rosemberg, 2002a, p. 47)

Assim, observamos, são nos documentos do PRELAC que encontramos reafirmado, com mais veemência, o "protagonismo das famílias", tanto como agentes educativos quanto unidade a ser educada. Como agentes educativos, transfere-se a responsabilidade da realização de atividades ou ações junto às crianças que, via de regra, deveriam ser desenvolvidas em instituições educativas. Como unidades a serem educadas, supõe-se que o provimento de informações acerca de aspectos nutricionais, de saúde e higiene, pode constituir-se em poderosos recursos no combate à mortalidade das crianças e no desenvolvimento de suas potencialidades cognitivas, condições consideradas necessárias ao bom aproveitamento escolar futuro. No entanto, quando se discute a educação infantil sem qualquer referência ao seu provimento pela esfera pública, estamos diante de uma transferência de responsabilidades do Estado para as famílias e “comunidades", deslocando esse nível educativo das políticas universais públicas para o plano das políticas compensatórias e focalizadas.

A focalização de políticas educativas, referenciada sobretudo na concepção de equidade, toma como pressuposto, conforme Cury (2005), a forma clássica de se fazer justiça tratando desigualmente os desiguais (CURY, 2005). Ainda conforme o autor, "a relação entre direito à igualdade de todos e o direito à equidade, em respeito à diferença, no eixo do dever do Estado e do direito do cidadão não é uma relação simples" (CuRY, 2005, p. 16).

Os ditames dos processos de integração econômica internacional observados nas últimas décadas, o acirramento das desigualdades sociais, gerando, entre outros aspectos, o alastramento do desemprego estrutural, "a redefinição do papel do Estado e sua consequente retração no plano da intervenção social, adicionada às crescentes limitações fiscais da 
ação pública, compõem um panorama crivado de restrições não apenas para ampliação da cidadania, senão também para a preservação de sua substância já cristalizada de direitos" (LAVALLE, 2003, p. 81).

De acordo com Kerstenetzky (2003), só seria possível se falar de uma justa distribuição de oportunidades se as escolhas individuais fossem mesmo livres. Para tanto, os sujeitos deveriam ter além da igualdade no que concernem seus direitos civis e econômicos, oportunidades iguais nos seus direitos

políticos (de participação do processo de decisão coletiva, cujos resultados afetam suas chances de realização), sociais (por exemplo, acesso à educação e à saúde) e econômicas (renda e riqueza), para a promoção das quais seria necessária uma política explicitamente redistributiva. (KeRstenetZKy, p. 79)

Dentro dessa lógica, as políticas sociais ${ }^{4}$ são principalmente residuais, tendo ação direta sobre os segmentos que estão fora dos processos integradores, de forma que a focalização se torna um componente da racionalidade do sistema. A grande política seria a econômica, de forma que a política social sofre uma minimização, sendo transformada em um apêndice no processo de eficiência proclamado pelo mercado. $\mathrm{O}$ imperativo do mercado, ou seja, da eficiência, acaba por superar o dos direitos (KerstenetzKy, 2003).

Outro aspecto também presente nas políticas focais é a noção de focalização como uma ação reparatória que, na atualidade, é traduzida pelas denominadas políticas afirmativas, as quais visam

corrigir as lacunas deixadas pelas insuficiências das políticas universalistas. Com isso se pretende equilibrar uma situação em que a balança sempre tendeu a favorecer grupos hegemônicos no acesso aos bens sociais, conjugando assim ao mesmo tempo, por justiça, os princípios de igualdade com o de equidade. (CuRY, 2005, p. 24)

Neste sentido, o documento do Prelac indica que,

para se obter maior equidade é importante focalizar os recursos nas zonas e centros de maiores pobreza ou vulnerabilidade, com o objetivo de baixar os altos indicies de repetência e evasão, melhorando, assim, a eficiência interna do sistema. (Unesco/Prelac, 2002a, p. 24, grifos nossos). 
Assim, a ênfase do Prelac é para políticas redistributivas compensatórias e não políticas redistributivas estruturais que implicariam em reformas profundas, como, por exemplo, reforma agrária e reforma tributária. A diferença entre essas concepções reside no fato de que, na primeira forma, resguarda-se o direito universal à vida e, na segunda, estariam sendo "atendidos a efetivação de outros direitos universais, mais sensíveis às desigualdades socioeconômicas, como os direitos civis, políticos e econômicos" (KERSTENETZKY, 2003, p. 83).

A problemática da diferença encontra-se também presente no documento-base do Prelac quando aborda questões relacionadas ao sucesso ou fracasso dos alunos, apontando-se para a necessidade de propostas pedagógicas diferenciadas compatíveis com as necessidades dos alunos. Neste sentido, a idéia é de que percursos escolares individualizados seriam condição para redução dos altos índices de reprovação e evasão:

com a grande expansão da educação básica verificou-se maior diversidade de alunos que não encontram respostas adequadas a suas necessidades educacionais e características específicas, ficando marginalizados e excluídos de forma mais ou menos explícita das oportunidades educacionais. (Unesco/Prelac, 2002a, p. 13)

Essa é uma idéia que perpassará todo o documento, constituindose em um mecanismo de legitimação às proposições apresentadas; se é certo, por um lado, que a ampliação do acesso escolar a grupos sociais historicamente excluídos produz novas demandas socioeducativas para as escolas, por outro, também sabemos que a segmentação da função educativa da escola, tendo por referência diversidades culturais resultantes muitas vezes de desigualdades sociais, efetivamente não se constitui em medida de sua democratização. Contrariamente, tal posicionamento pode facilitar o retorno do discurso meritocrático e a assunção das discussões psiconeurológicas, numa perspectiva de entender as diferenças a partir de suas constituições psicofísicas, como móvel orientador dos currículos escolares.

No âmbito da educação infantil, a idéia da educação das potencialidades das crianças, compreendidas numa perspectiva cognitivista de cunho neurológico, tem reforçado a idéia de ambientes favoráveis/desfavoráveis às aprendizagens, motivo pelo qual a educação dos pais figura como um dos elementos centrais. Esta também é a base do currículo 
da fundação High/Scope, cujo fundamento para sua ação educativa é a intervenção não apenas junto às crianças, mas também junto às famílias, de modo que estas possam aprender como criar boas oportunidades de desenvolvimento para seus filhos, organizando o seu próprio ambiente doméstico, utilizando e/ou produzindo materiais com recursos disponíveis em casa etc. Enfim, trata-se de moldar as estratégias de socialização familiares, os comportamentos e as atitudes dos pais,

a partir de preceitos oriundos dos campos da psicologia e da medicina. Ainda que se compreenda que o direito da criança ao desenvolvimento integral é também responsabilidade da família, contudo, como direito implica diretamente também a obrigação do Estado; fato esse negado na própria lógica que orienta programas dessa natureza. (CAMPOS; CAMPOS, 2006, p. 08)

\section{CONSIDERAÇÕES FINAIS}

A educação ao longo da vida, fortemente difundida a partir do Fórum Mundial de Educação para Todos (EPT, 1990), juntamente com conceitos como equidade social, eficácia, eficiência, entre outros, acaba definindo o papel da educação neste novo cenário mundial. Nas indicações provenientes dos projetos analisados, duas linhas de compromisso em relação à educação se evidenciam: focalização e combate à pobreza. Estas orientações estão presentes, de forma que a educação

deixa de ser concebida como direito social e se discute em termos de um bem que se adquire em um mercado regional, relegando aos Estados um papel subsidiário que garante um serviço educativo somente para quem não pode consegui-lo no mercado. (GenTILLI, 2005, p. 19)

A concepção da educação como serviço, e não como direito, justificaria então a atenção do Estado às crianças e famílias em situação mais "vulnerável". ${ }^{5}$ Assim, observamos que na AIIA ressalta-se que, no combate à pobreza e à pobreza extrema, é muito importante garantir um "melhor começo de vida às crianças" em seus primeiros anos. Seguindo esta linha, observamos ainda que as justificativas para os investimentos na educação da infância são fortemente condicionados pela perspectiva do desenvolvimento de recursos humanos, tendo em vista a capacidade 
produtiva futura e a possibilidade de gerar uma distribuição mais equitativa.

Essa argumentação se contrapõe à concepção de educação direcionada para a pequena infância como direito universal e inalienável, tendo como finalidade as pessoas e não a sua capacidade produtiva (OLIVEIRA, 2000). Em outras palavras, quando analisamos os documentos, a justificativa apresentada para que os países invistam na educação infantil pauta-se, acima de tudo, na perspectiva dessa ser uma boa estratégia para romper com os ciclos de pobreza. Para isso, são referenciados, nestes documentos, os estudos ou as pesquisas que procuram comprovar que as crianças que têm acesso à educação inicial possuem melhores rendimentos nos anos subsequentes de ensino, oportunizando melhores chances de se inserirem no mercado de trabalho, tendo por isso, também, melhores retornos posteriores em termos de renda. Enfim, estabelecese uma relação direta entre elevação de escolaridade-emprego-renda. São retomados, desse modo, os preceitos da teoria do capital humano. Outrossim, nos parece que a educação não é compreendida em suas possibilidades democráticas,

não é entendida como a necessidade de fazer as crianças do povo entrarem nas formas simbólicas, no universo dos saberes socialmente construídos e das grandes obras-primas da humanidade. Ela significa que é preciso dotá-las das competências operacionais que correspondem a seu desenvolvimento cognitivo, a suas necessidades particulares, a seus interesses e a seus projetos profissionais e que lhes permitirão tanto se integrar no emprego quanto responder às "necessidades vitais". (LAVAL, 2003, p. 308)

Parece-nos ainda que a educação para a pequena infância, em sistemas públicos de ensino, em unidades educativas especificamente voltadas para esse fim, não é entendida como um serviço social e educacional de interesse público. Mesmo que seja possível observar nos documentos que analisamos a presença de discursos e ações que apontam para políticas sociais, em especial a partir da década de 2000, estes posicionamentos ficam subsumidos pela ausência de ações efetivas em prol de maior compromisso e responsabilidade dos governantes da região na sua execução. Fundamentados em Gentilli (2005), poderíamos afirmar que as linhas anteriores de mercantilização e focalização da educação ainda se 
sustentam, porém articuladas agora aos discursos da democratização, inclusão e direitos sociais

Outro aspecto a ser destacado diz respeito à constante reiteração nas iniciativas supranacionais analisadas, à necessidade de programas intersetoriais; mas não abordam esta proposta como uma meta de "unificação de objetivos e universalização de oferta para todos os grupos etários numa atenção conjunta às necessidades da criança e da família" (HADDAD, 2006, p. 535). Assim, os subsídios públicos são destinados em menor proporção para a educação de crianças menores de três anos, de modo significativo nos países em desenvolvimento, nos quais a responsabilidade pelos primeiros anos da criança está ainda sob responsabilidade das famílias e, de modo particular, das mulheres. Mesmo em alguns países desenvolvidos, como Estados Unidos e Inglaterra, "a educação e guarda das crianças são vistas essencialmente como tarefas de cunho privado, que deverão ser administradas por cada família e não como questões que exijam um sólido compromisso público" (UNESCO/OECD, 2002, p. 129).

Essa tendência acaba por incentivar diversas alternativas não-formais de atendimentos, na maioria das vezes, de qualidade questionável. Do mesmo modo, acabam por respaldar os programas direcionados para educar as famílias, em detrimento de investimentos em uma política pública para educação de todas as crianças. Como resultado, o acesso aos serviços públicos em período integral permanece limitado às famílias de baixo nível socioeconômico ou às crianças consideradas "em risco" ou em situação vulnerável, como postulam os documentos internacionais.

Assim, essas análises nos indicam que, ainda que os programas e os projetos definam objetivos distintos, ênfases diferentes, há aspectos comuns entre eles, ou melhor, existem eixos comuns que sempre são reiterados nos diversos documentos produzidos. De modo mais específico, observamos concepções comuns que acabam por direcionar as propostas e indicações que de forma sintetizada podem ser enunciadas:

a) a necessidade de desenvolvimento de atendimento integrado à infância, ou seja, a educação infantil deve ser integrada com outras ações (área de saúde, nutrição, prevenção maternal etc.);

b) a educação infantil é discutida na lógica das políticas compensatórias, logo as indicações são para programas focais e não para o desenvolvimento de políticas de educação infantil; 
c) a educação das famílias é considerada elemento-chave para o bom desenvolvimento da criança, evitando atrasos posteriores. Neste sentido, a educação dos pais se organiza com base na lógica de "estimulação infantil", ou seja, os pais devem ser educados para saberem como estimular o desenvolvimento das crianças e, dessa forma, potencializarem e desenvolverem suas competências;

d) a indicação para que a ampliação do atendimento seja utilizando formas "alternativas", isto é, atendimentos não-formais.

Enfim, de maneira geral, o que podemos observar é que as propostas para educação da infância não se pautam nos princípios de direito e igualdade. Estes são substituídos pelos princípios da equidade e competitividade. E, como já pontuado, a educação, e por extensão a educação para pequena infância, é inserida numa nova ordem, afastando-se de sua função social emancipatória.

Em síntese, seguindo essa premissa, as indicações dos organismos orientam-se para a necessidade de uma reforma diretamente nas políticas sociais: a lógica universalista de direitos passa a ser substituída, em especial após a década de 1990, pela lógica da focalização, centrada na intervenção sobre segmentos sociais considerados carentes ou vulneráveis. Com isto, os governos nacionais podem adotar uma política de restrição dos gastos sociais atuando prioritariamente por meio de programas compensatórias dirigidos às populações excluídas. Assim, o poder público que deveria organizar sistemas adequados para garantir a participação de todos aos bens da coletividade e uma melhor distribuição desses bens - princípio a partir do qual as políticas públicas são forjadas -, se volta para o desenvolvimento de diferentes programas estratégicos e compensatórios da assistência focalizada.

\section{ABSTRACT}

The aim of this article is to discuss the repercussions of the indications for early childhood education produced by international organizations. We analyzed, especially, two ongoing projects in Latin America, one coordinated by UNES$\mathrm{CO}$ and the other, by the OEI. To examine the impact of these indications we studied the main documents, examining the concepts and logic on which they are based, as well as their differences and similarities. According to information 
found in the projects, early childhood education is an important strategy for fighting poverty and a means of promoting equality, focusing on children and their families who live in a "socially vulnerable situation". As a consequence, early childhood education is categorized as a service, moving away from the concept of a public asset to which children and their families are entitled.

Keywords: Childhood education. Public policies. International organizations. Education and reducing poverty.

\section{NOTAS}

1. Por política social compreendemos: "as ações que determinam o padrão de proteção social implementado pelo Estado, voltadas, em princípio, para a redistribuição dos benefícios sociais visando à diminuição das desigualdades estruturais produzidas pelo desenvolvimento socioeconômico" (HOFLING, 2001, p. 31).

2. Segundo Rosemberg (2002a), a ONU, por meio das grandes conferências internacionais dos anos 1990 (Conferência do Desenvolvimento, da População, da Mulher, da Educação para Todos), tem participado ativamente na demarcação dessa vulnerabilidade.

3. Essa declaração resultou da I Reunião Intergovernamental do Projeto Regional de Educação para América Latina e Caribe, em 2002.

4. Essa declaração, conforme já enunciado, corresponde à XI Cúpula IberoAmericana de Chefes de Estado e de Governo, que ocorreu em Lima, Peru, por ocasião da qual foi aprovada a Agenda Ibero-Americana para a Infância e a Adolescência.

5. Em termos gerais, e incorrendo no risco de simplificar, no campo das teorias da justiça há diferentes formas de definição de justiça. Assim, temos a teoria denominada de concepção fina de justiça, na qual o Estado tem uma participação ínfima na promoção de justiça social. É ao mercado nesta concepção que é atribuída a função de distribuição de vantagens socioeconômicas, e ao Estado de Direito zelar pela lei e ordem necessária ao funcionamento econômico. Em contraposição a essa concepção existe a de justiça social, que reconhece o Estado como tendo uma função importante na complementação da distribuição de vantagens socioeconômicas. Para uma discussão mais aprofundada, ver Kerstenetzky (2003). 


\section{REFERÊNCIAS}

ANTUNES, F. Reformas do Estado e da Educação: o Caso das Escolas profissionais em Portugal. Revista Brasileira de Educação, n. 29, mai./jun./jul./ago., 2005a.

Globalização e europeização das políticas educativas: percursos, processos e metamorfose. Sociologia, n. 47, jan., 2005 b.

BRASIL. Plano Nacional de Educação. 2001.

CAMPOS, A. L. Proyecto Educativo para el Desarrollo Humano: um Instrumento pedagógico inovador. III Seminário Internacional da Primeira Infância. Porto Alegre, 2005.

CAMPOS, R.; CAMPOS, R. F. A educação das famílias como política educacional: uma análise do programa família brasileira fortalecida. $29^{\circ}$ Reunião Nacional de Pesquisa em Educação/ANPED. Caxambu, 2006.

CAMPOS, R. Educação infantil e organismos internacionais: uma análise dos projetos em curso na América Latina e suas repercussões no contexto nacional. Florianópolis. 2008. Tese (Doutorado em Educação) -Universidade Federal de Santa Catarina.

CEPAL/UNESCO. Educação e conhecimento: eixo da transformação produtiva com equidade. Brasília: Ipea/Cepal/Inep, 1990.

CURY, C. R. J.. Políticas inclusivas e compensatórias na educação básica. $C a$ dernos de Pesquisa. v. 35, n. 124, São Paulo, jan./abr., 2005.

EVANGELISTA, O. Governação global e diretrizes internacionais para a educação na União Européia. Entrevista com Fátima Antunes. Perspectiva, v. 23, n. 02, Florianópolis, jul./dez. 2005.

GENTILE, P. La educación en las cumbres de las Américas: su impacto en la democratización e los sistemas educativos. Ensayos \& Investigaciones del Laboratorio de Políticas Públicas. Buenos Aires, n. 01, 2005.

HECKMAN, James. The real question is how to use the available funds wisely. The best evidence supports the policy prescription: Invest in the Very Young. 2000. Disponível em: $<$ http://www.ounceofprevention.org/downloads/publications/Heckman.pdf>.

HECKMAN, J.; CUNHA, F. Credit Constraints, Family constraints and Optimal polices to reduce inequality and promote productivity. Conferência Internacional sobre Pré-escola. Fundação Getulio Vargas, Rio de Janeiro, 2005.

IVO, A. B. L. A reconversão do social: dilemas da redistribuição no tratamento focalizado. São Paulo em Perspectiva, 18 (2), 2004. 
KERSTENETZKY, C. L.Desigualdade como questão política. Observatório da Cidadania, 2003a. Disponível em: $<$ http://www.socialwatch.org/es/informeImpreso/pdfs/panorbrasileiroe2003_bra.pdf.>.

LAVAL, C. A escola não é empresa: o neoliberalismo em ataque ao ensino público. Trad. de Maria Luiza M e Carvalho e Silva. Londrina: Planta, 2004.

LAVALLE, A. G. Cidadania, igualdade e diferença. Revista Lua Nova, n. 59, 2003.

OEI. Declaración de La Habana: Calidad de la educación: equidad, desarrollo e integración ante el reto de la globalización. IX Conferencia Iberoamericana de Educación. Habana, 1999.

. Declaración de Panamá: La Educación Inicial en el Siglo XXI. X Conferencia Iberoamericana de Ecuación. Ciudad de Panamá, jul. 2000a.

. XI Conferencia Ibero-Americana de Educação. Valência (Espanha), março, 2001a.

. Declaración de Lima: "Agenda Iberoamerica para la niñez e la adolescência". III Conferencia Iberoamericana de Ministras, Ministros y Altos Responsables de La Infancia y Adolescencia. Lima, Oct., 2001b.

OLIVEIRA, D. A. Educação básica: gestão do trabalho e da pobreza. Petrópolis, RJ: Vozes, 2000.

ONU. Relatório do Comitê Ad Hoc Pleno da Vigésima Sétima Sessão Especial da Assembléia Geral: Um mundo para as crianças. Nova Iorque/Brasil, 2002.

ROSEMBERG, F. Ano 2000: Educação da pequena infância. São Paulo em Perspectiva. 3(3), jul./set., 1989.

. Organizações multilaterais, estado e políticas de educação infantil. Cadernos de Pesquisa, São Paulo, n. 115. mar. 2002a.

. Do embate para o debate: educação e assistência no campo da educação infantil. In: MACHADO, M. L. (Org.). Encontros e desencontros em educação infantil. São Paulo: Cortez, 2002b.

ROSSETTI-FERREIRA, M. C.; RAMON, F.; SILVA, A. P. S. Políticas de atendimento à criança pequena nos países em desenvolvimento. Cadernos de Pesquisa, n. 115, mar. 2002.

SHIROMA, E. O.; CAMPOS, R. F.; GARCIA, R. M. C. Subsídios teóricos para construção de uma metodologia para análise de documentos e política educacional. In: SHIROMA, E. O. Dossiê: Uma metodologia para análise conceitual de documentos sobre política educacional. Florianópolis, 2004. (Mimeo.). 
TEDESCO, J. C.; LÓPEZ, N. Las condiciones de educabilidad de los ninõs $y$ adolescentes en America Latina (versión preliminar). IIPE: Buenos Aires, 2002.

UNICEF. Situação mundial da infância 2006: excluídas e invisíveis. Brasil, 2006.

UNESCO. Declaración de la Habana. Habana, 2002.Disponível em: <www. unesco.cl $/ \mathrm{medios} /$ biblioteca/documentos/prelac_declaracion_habana_esp. pdf $>$.

UNESCO/PRELAC. Proyecto Regional de Educación para América Latina y el Caribe. Habana, 2002a. Disponível em: <www.unesco.cl/medios/biblioteca/ documentos/prelac_proyecto_regional_educacion_esp.pdf $>$.

. Informe de Seguimiento de la EPT en el Mundo - Bases sólidas: atención y educación de la primera infancia. Ediciones Unesco, Paris, 2007.

UNESCO/OECD. Educação e cuidado na primeira infância: grandes desafios. Trad. Guilherme João de Freitas Teixeira. Brasília: Unesco Brasil, OECD, Ministério da Saúde, 2002.

WINTERSBERGER, H. Infancia y ciudadanía: el orden generacional del estado de bienestar. Política y Sociedad, v. 43, n. 1, Facultad de Ciencias Políticas y Sociología. Madrid: Campus de Somosaguas, 2006.

ZICCARDI, A. (Org.) Pobreza, desigualdad social y ciudadanía - Los límites de las políticas sociales en América Latina. Buenos Aires: CLACSO, 2001. 